\title{
Smoking status on subsequent readmission to hospital: The impact of inpatient brief interventions for smokers
}

\author{
Kathryn J. Vitangcol',2, Cheneal Puljevic ${ }^{2,3}$, Deepali Gupta ${ }^{4,5,6}$, Centaine L. Snoswell ${ }^{1,2,4}$
}

\section{Dear Editor,}

Tobacco smoking is a leading cause of preventable morbidity and mortality globally, resulting in social and economic costs, making it a focus for many countries, including Australia ${ }^{1-5}$. One such initiative includes the implementation of smoke-free policies in hospitals, and the provision of nicotine replacement therapy (NRT) and/or brief behavioral interventions to encourage smoking cessation $^{6-8}$.

As part of this policy and to improve the uniformity with which staff support patients to quit smoking, the Smoking Cessation Clinical Pathway (SCCP) was implemented throughout Queensland Health hospitals in $2015^{9}$. The SCCP is a form (paper or digital) that guides hospital clinicians through screening patients' smoking behaviors and then providing NRT or other support, such as Quitline referral, to facilitate smoking cessation'. Here we describe a brief analysis of retrospective data examining the smoking status of patients who received the SCCP and were subsequently readmitted to a large metropolitan hospital in Queensland, Australia.

Patients were excluded from the analyses if they were readmitted for less than 24 hours or were readmitted with no smoking status recorded. Patients were included if they were documented as being a current smoker in their integrated electronic medical record. Final readmission smoking status was recorded as one of three options: 1) Quit (self-reported as ex-smokers at a subsequent readmission); 2) Relapsed (patients with multiple admissions and self-reported being an ex-smoker and then a smoker); and 3) Unchanged. We calculated descriptive statistics and performed a regression analysis whose findings were largely non-significant so are not reported here.

We extracted records for 504 patients who were discharged from hospital between January and April 2016. From this sample of patients, 387 (73\%) received an SCCP intervention in at least one of their admissions to hospital. At first readmission, 166 (33\%) patients reported having quit smoking, while 339 (67\%) reported continuing to smoke. Of the 166 that initially quit, 129 remained abstinent (78\%), while $37(22 \%)$ relapsed by their final readmission within the time period examined. Smoking cessation rates were similar among patients who had an SCCP completed at any previous admission (47\% had quit, $\mathrm{n}=60)$, and those who did not $(53 \%, \mathrm{n}=69)$. The SCCP intervention entails provision of NRT during patient admission to assist with nicotine withdrawal as part of the hospital's smoke-free campus policy, regardless of the patient's intention to quit.

This study found that $26 \%$ of 504 patients who received a brief intervention during their hospital admission had quit smoking by a subsequent readmission to hospital, and that smoking cessation rates were similar regardless of SCCP
AFFILIATION

1 Centre for Online Health, Faculty of Medicine, The University of Queensland, Brisbane, Australia 2 Centre for Health Services Research, Faculty of Medicine, The University of Queensland, Brisbane, Australia

3 Centre of Research Excellence on Achieving the Tobacco Endgame,

School of Public Health, The University of Queensland, Brisbane, Australia

4 Pharmacy Department, Princess Alexandra Hospital, Brisbane, Australia

5 Pharmacy Department, Queen Elizabeth II Jubilee Hospital, Brisbane, Australia

6 Statewide Respiratory Clinical Network, Clinical Excellence Division, Queensland Health, Queensland Government, Brisbane, Australia

\section{CORRESPONDENCE TO}

Kathryn J. Vitangcol. Centre for Online Health, Faculty of Medicine, The University of Queensland, Building 33 Ground Floor, Princess Alexandra Hospital campus, QLD 4102, Brisbane, Australia. E-mail: k.vitangcol@uq.edu.au ORCID ID: https://orcid.org/0000-0002-62798033

\section{KEYWORDS}

tobacco, brief intervention, cessation, NRT, SCCP

Received: 22 October 2021 Revised: 11 November 2021 Accepted: 16 November 2021 
completion. Limitations of this study include the lack of a comparator group and quantification of provider compliance. Future studies with a comparator group, structured follow-up of patients and a longer timeframe are planned; this preliminary investigation indicates that the SCCP may positively affect smoking cessation behavior.

Rigotti et al. ${ }^{10}$ pooled 50 studies and concluded that out of 13613 patients, experience of an intervention led to a $37 \%$ smoking cessation rate ${ }^{10}$. This rate is comparable to the reported cessation rate at 12 months for this study, providing positive evidence that supports the effectiveness of the SCCP and policy changes in Queensland Health. The results of this study highlight the importance and effectiveness of healthcare workers role in providing smoking cessation and having an institutional policy. This provides supporting evidence for other hospitals of other areas in Australia, or globally, to implement similar interventions.

\section{REFERENCES}

1. World Health Organization. Tobacco. World Health Organization; 2021. July 26, 2021. Accessed November 11, 2021. https://www.who.int/news-room/fact-sheets/ detail/tobacco

2. World Health Organization. MPOWER - Tobacco Free Initiative. World Health Organization; 2021. Accessed November 11, 2021. https://web.archive.org/ web/20210528043910/https://www.who.int/tobacco/ mpower/en/

3. GBD 2019 Risk Factors Collaborators. Global burden of 87 risk factors in 204 countries and territories, 19902019: a systematic analysis for the Global Burden of Disease Study 2019. Lancet. 2020;396(10258):12231249. doi:10.1016/S0140-6736(20)30752-2

4. Alcohol, tobacco \& other drugs in Australia. Australian Institute of Health and Welfare; 2020. Updated September 24, 2021. Accessed November 11, 2021. https://www. aihw.gov.au/reports/alcohol/alcohol-tobacco-otherdrugs-australia/contents/about

5. Collins DJ, Lapsley HM. The costs of tobacco, alcohol and illicit drug abuse to Australian society in 2004/05. Australian Government, Department of Health and Ageing; 2008. Monograph Series 64. Accessed November 11, 2021. https://webarchive.nla.gov.au/ awa/20080719000503/http://www.nationaldrugstrategy. gov.au/internet/drugstrategy/publishing.nsf/Content/ 34F55AF632F67B70CA2573F60005D42B/\$File/ mono64.pdf

6. Smoking policy. Queensland Government, Metro South Health; 2021. Updated November 4, 2021. Accessed
November 11, 2021. https://metrosouth.health.qld.gov. au/patients-and-visitors/your-time-in-hospital/smokingpolicy

7. Northern Territory Tobacco Action Plan 2019 - 2023: Alcohol and Other Drug Service. Northern Territory Government; 2019. Accessed November 11, 2021. https:// apo.org.au/sites/default/files/resource-files/2019-05/ apo-nid239616.pdf

8. Wiggers J, Vashum K, Wolfenden L, et al. Implementing nicotine dependence and smoking cessation care in hospitals. Sax Institute; 2016. November 11, 2021. https://apo.org.au/sites/default/files/resourcefiles/2016-06/apo-nid69606.pdf

9. Smoking Cessation Clinical Pathway. Queensland Government; 2015. Metro South Health. July 10, 2015. Updated November 18, 2019. Accessed November 11, 2021. https://web.archive.org/web/20200403194851/ https://metrosouth.health.qld.gov.au/innovationcentral/ project/smoking-cessation-clinical-pathway

10. Rigotti NA, Clair C, Munafò MR, Stead LF. Interventions for smoking cessation in hospitalised patients. Cochrane Database Syst Rev. 2012;5(5):CD001837. doi:10.1002/14651858.CD001837.pub3

\section{ACKNOWLEDGEMENTS}

Thank you to all of the Metro South Health employees and placement students who assist with data collection, including, but not limited to, John Watts, Vikki Goldup, Karl Winckel, and the decision support team.

\section{CONFLICTS OF INTEREST}

The authors have completed and submitted the ICMJE Form for Disclosure of Potential Conflicts of Interest and none was reported.

FUNDING

There was no source of funding for this research.

ETHICAL APPROVAL AND INFORMED CONSENT

Ethical approval was granted by Metro South HREC (HREC/17/QPAH/156).

DATA AVAILABILITY

Data sharing is not applicable to this article as no new data were created.

PROVENANCE AND PEER REVIEW

Not commissioned; internally peer reviewed. 